\title{
Relationship between pressure and digital vasculitis in rheumatoid disease
}

\author{
J. C. W. EDWARDS
}

From Guy's Arthritis Research Unit, Guy's Hospital Medical School, London Bridge, London SE1 9RT

SUMMARY The sites of 92 rheumatoid nailfold lesions were compared with sites of pressure as indicated by tissue blanching during gripping. A close correspondence between sites of blanching and sites of vasculitis was found, and this is discussed in relation to the possible role of vascular compression and blood stasis in the development of rheumatoid vasculitis.

A relationship between exposure to physical forces and localisation of both nodules and synovitis in rheumatoid disease is well recognised, though the mechanism is poorly understood (Bywaters, in press). If all focal rheumatoid lesions are initiated by a similar process, one might also expect to see skin vasculitis at sites of exposure to physical force. The purpose of the present study is to report the sites of rheumatoid skin vasculitis at the nailfold in an unselected group of patients and assess whether these relate to sites of tissue stress. Visible blanching of the tissue was used as an index of tissue stress, since blood vessel compression with subsequent local stasis may be relevant to localisation of vasculitis. Stasis has been previously implicated in the localisation of a wide variety of vasculitic diseases (Ryan, 1976).

\section{Patients and methods}

All patients with rheumatoid arthritis seen as outpatients and inpatients at Guy's Rheumatology Unit by the author were carefully examined for nailfold vasculitis. The first 10 consecutive cases of nailfold vasculitis observed were studied.

\section{MAPPING OF LESIONS}

A standard map of a fingernail was designed (Fig. 1). Measurements from point ' $a$ ' were taken in $X$ and $Y$ co-ordinates and standardised so that the nail "width represented 10 units. Each lesion was described to the nearest unit-for example, X6Y6. The $\mathrm{X}$ axis was defined as being in a radial (thumbwards) direction for ease of comparing right and left hands.

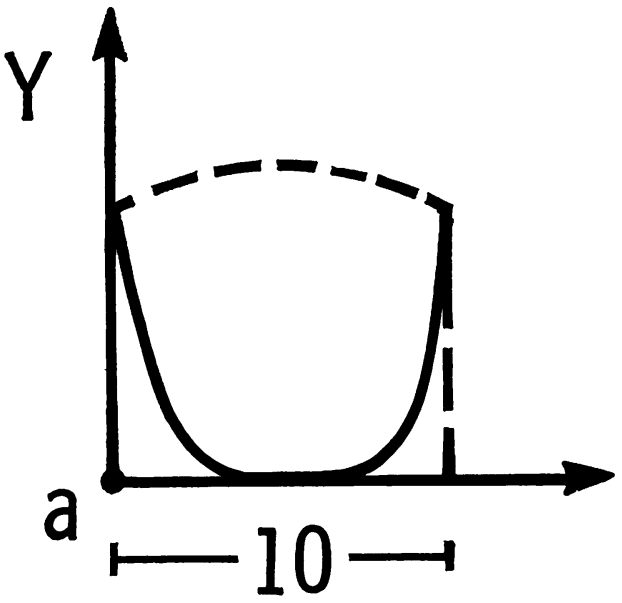

Fig. 1 Finger-nail map used to plot precise site of digital vasculitis and areas of blanching.

\section{MAPPING OF BLANCHING}

Patients were asked to perform two manoeuvres: to pinch thumb and index finger together, and maximally to flex all digits as in a power grip. The assumption was made that the common patterns of gripping consist of either one or a combination of these manoeuvres. Areas of blanching around the nail were recorded. The extent of blanching varied with effort. Therefore only the presence or absence of blanching at the base, the side (paronychium), and at the distal edge were recorded for each digit.

\section{Results}

Ninety-two lesions were recorded from 10 patients, and these were plotted on to a series of nail maps 
together with patterns of blanching. A map was drawn for each group of patients with the same blanching patterns for a specific digit (Fig. 2). Most patients performed pinch grip between index and thumb, some by adduction and some by true opposition. In the latter, bilateral paronychial blanching occurred on the thumb. The distal interphalangeal joint of the right index of patient 7 was dislocated. Pinch grip was therefore performed with thumb and middle finger combined because of weakness and deformity. Nail-base blanching occurred in patients $2-6,9$, and 10 , but not in patients 1,7 , and 8.

Only 13 of 92 lesions occurred away from blanched areas, there being a strong predominance of lesions on the radial aspect of the index and ulnar aspect of the thumb at sites of blanching during pinch. Lesions appeared to occur chiefly at the edge of blanched zones, but the recording method was not precise enough to establish this firmly.

\section{Discussion}

Blanching of the nail fold (paronychim) and nail base occurs in 2 distinct patterns during gripping. During pinch or precision grip the paronychium is compressed, and the area of blanching occurs, including the paronychium itself and often extending in a crescent on to the distal nail bed. In true opposition this crescent may extend right across and fuse
Little

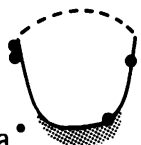

Pts: $2,3,4,5,6$, 9,10

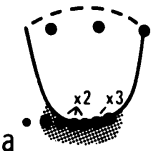

Pts: $2,3,4,5,6,10$

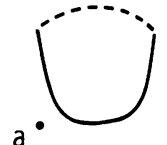

Pts: $1,7,8$

$$
9,10
$$

$\underline{\text { Ring }}$

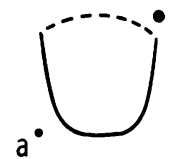

Pts: $1,7,8$

Middle

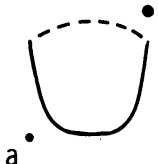

Pts: $1,7(\mathrm{~L}), 8$

Pts: 7(R)

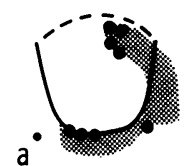

Pts: 9

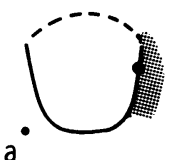

Index
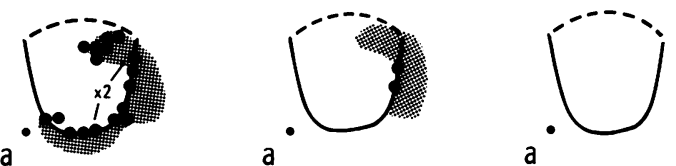

Pts: 7(R)

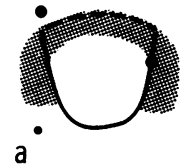

Pts: 8

Pts: $2,3,4,5,6$, 9, 10

Pts: $1,7(\mathrm{~L})$

\section{Thumb}
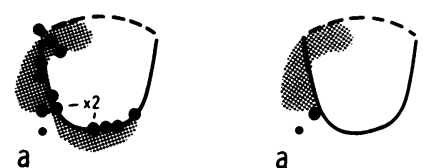

a

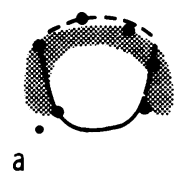

- Lesions

Blanching

Pts: 7(R), 8

Pts: $2,3,4,5,6$, 9,10

Pts: $1,7(\mathrm{~L})$

Fig. 2 Distribution of sites of lesions and blanching in 10 patients with rheumatoid arthritis. Where more than one lesion occurred at a single site this is indicated in the figure. 
with the blanched area of the opposite paronychium. In grip patterns involving maximal flexion of a digit-'power grip' or 'baggage grip' for instancea second type of blanching occurs. The base of the nail blanches not from extrinsic pressure but presumably because of internal forces set up within the tissues. This basal blanching only occurs with extreme proximal interphalangeal and distal interphalangeal flexion in the normal hand, but in some rheumatoid patients with loss of flexion it occurs much earlier. It others, chiefly with flail or deformed digits, it may not occur at all. In view of this variation sites of vasculitis in each patient have been compared with the sites of blanching peculiar to that patient.

It appears from the observations that nail-fold vasculitis is not randomly distributed. There is a marked preponderance of paronychial involvement on the radial aspect of the index and ulnar aspect of the thumb. The overall correspondence of sites of vasculitis and sites of blanching during the 2 chosen manoeuvres supports the suggestion that tissue compression may be involved in localisation. The correspondence of idiosyncratic blanching patterns in certain patients with vasculitic sites (for example, patient 7) also supports this suggestion. It is of interest in this context that during the search for vasculitic nail-fold lesions no lesions were found on patients whose digits were so severely affected that they had lost all ability to form a grip involving the terminal phalanges.

If there is a causal relationship between tissue compression and sites of vasculitis, the exact mechanism must remain speculative. During the study it was noted that sites of vasculitis were most frequent at the edge of areas of blanching. This suggests the possibility that at the edge of an area of vascular compression there are small vessels containing static blood and that this combination of vascular compression and the presence of static blood may facilitate microvascular damage.

I thank Dr R. Grahame, Dr T. Gibson, and Dr G. S. Panayi for allowing me to study their patients, and Dr A. Kay for her helpful criticism.

\section{References}

Bywaters, E. G. L. (In press). Pathogenesis of rheumatoid arthritis and effects of movement. European Symposium on Rheumatoid Arthritis, Rheumatology and Rehabilitation. Ryan, T. J. (1976). Microvascular Injury, p. 24. W. B. Saunders: Eastbourne, Toronto, and Philadelphia. 